Canadian Oncology

Nursing Journal

Revue canadienne

de soins infirmiers

en oncologie

Volume 28, Issue 4 • Fall 2018

elSSN: 2368-8076 


\section{Reaching professional consensus on pivot nurse in oncology interventions in the goal of staff planning in Quebec}

by Andréanne Saucier and Alain Biron

\begin{abstract}
Nearly 250 pivot nurse in oncology (PNO) are practising in Quebec to support cancer patients. Yet, it is increasingly obvious that this number is insufficient. A study was conducted to estimate the need for PNOs for the province. Professional consensus was reached using the nominal group technique and the Delphi method. The data obtained help to make staffing decisions based on findings measured in PNOs' current work reality. It is the authors' hope that these results will contribute to human resources planning that better meets the needs of cancer patients and their families.
\end{abstract}

\section{BACKGROUND}

$\mathrm{O}$ ncology nurse navigators (PNO) were introduced in 2005 in Quebec (Comité de l'évolution de la pratique infirmière en oncologie [CEPIO], 2005; Fillion et al., 2009; Fillion et al., 2010; Plante \& Joannette, 2009). These nurses are resource people for cancer patients and their loved ones, intervening from the diagnosis announcement throughout the cancer journey. One of the primary objectives for introducing this unique role was to reduce the fragmentation of care. More specifically, PNOs assess, educate, inform, support and coordinate to ensure continuity of care (Direction générale de cancérologie [DGC], 2008).

In Quebec, more than 49,100 people are diagnosed with cancer each year (Canadian Cancer Society's Advisory Committee on Cancer Statistics, 2014). Nearly 250 PNOs have been deployed across Quebec to support these patients (DLCC, 2011). Initially in this first deployment, the goal was to reach a ratio of 1 PNO for every 200 new cancer patients. This was the ratio used to plan the number of PNOs required for the province at that time

\section{ABOUT THE AUTHORS}

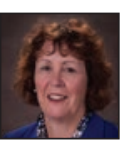

Andréanne Saucier, RN, MSc, Assistant Professor, Ingram School of Nursing, McGill University

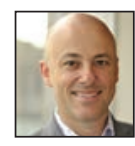

Alain Biron, RN, PhD, Assistant Director of Nursing, Professional practice, Assistant Professor, Ingram School of Nursing, McGill University

Address for correspondence: Alain Biron, McGill University Health Centre, 1650 Avenue Cedar, Montréal, QC H3G 1A4 Email: alain.biron@muhc.mcgill.ca

The authors would like to thank the Direction générale de cancérologie for their financial support and assistance in carrying out the study. The authors would also like to thank Catherine Nesbitt, study coordinator, and Myriam Skrutkowski for her assistance in developing strategies based on the study's findings.

DOI:10.5737/23688076284308313
(DLCC, 2007). Despite the increase in cancer diagnoses, the number of PNOs has remained mostly unchanged since 2011. It is increasingly obvious that the number of PNOs is probably insufficient. Indeed, this ratio has not been met in recent years.

Other than the number of people diagnosed each year, an estimate of the required staff calls for knowledge of the care that patients and their families require, as well as PNOs' true capacity (productivity) for case monitoring (Birch et al., 2007). A study on time and motions made it possible to obtain information on productivity (Biron \& Saucier, 2012). This study specified the time devoted to related tasks that are inherent to the work organization (i.e. non-productive and administrative tasks). The results showed that $22.4 \%$ of the PNOs' time is spent on these non-clinical tasks (Biron \& Saucier, 2012).

However, the level of care patients need is not yet known, thus hampering a more rigorous human resources planning. Various methods have been used to determine the level of nursing care (Spetz, 2008). For the most part, these methods were developed in the context of hospitalized patients. As a result, other options have to be used in the absence of proven methods, given the absence of a research-validated method for nurses in the outpatient context. Using the nominal group technique (NGT) or the Delphi method to reach professional consensus is one possible avenue when evidence is lacking. These techniques effectively reach a professional consensus (Hasson \& Keeney, 2011). It will thus be possible to establish professional consensus to determine patients' needs through the identification of nursing interventions deemed essential, as well as the time required to carry them out.

In this context, this study aimed to reach professional consensus on nursing interventions felt to be essential, as well as the time required to carry them out. The collected data will fill gaps in the information needed for better PNO staffing in Quebec. Ultimately, better planning will ensure a more equitable access for patients with cancer to these resources, while also minimizing the negative impacts understaffing can have on PNOs and patients.

\section{METHOD}

The method was divided into two phases. The first phase consisted of applying the nominal group technique (NGT) (Harvey \& Holmes, 2012). In the second phase, the results from the NGT were used to inform the Delphi method (Hasson \& Keeney, 2011) and reach consensus among all PNOs in Quebec on the interventions deemed necessary and the time required to perform them. The method underlying these two phases is described below. 


\section{Nominal group technique}

In this project, a group of experienced PNOs who are recognized as experts by their peers were asked to generate a list of interventions deemed essential and to come to an initial consensus on the time required to perform them.

Selection of the group of experts. A convenience sample of 12 expert PNOs was used. The research team contacted the appropriate administrators at the Agences de la santé et des services sociaux and the various university hospital centres to recruit this sample. Each administrator named at least 1 nurse who had at least three years of experience as an PNO and was recognized as an expert. To ensure equitable representation of the different sites, random drawing was used when more than four experts from the same site (at local, regional or supraregional levels) wished to participate in the project.

Procedure. Once the experts were selected, a working day was organized. These PNOs first received a letter describing NGT and inviting them to reflect on the interventions/activities they felt were professionally important in their PNO role, as well as the time required to carry out these tasks, considering the various steps of the illness trajectory (i.e. announcement of the cancer diagnosis and preparing for the first treatment, surgery, chemotherapy, radiation therapy, post-treatment follow-up and the transition from curative to palliative care).

The day began with an introduction to clarify some information that had been provided. Then, expert nurses drew up individually a list of potential interventions for the five steps of the care trajectory. The PNOs were instructed to draw on their own professional experience and opinions of what the PNOs' interventions should be to best meet the needs of the cancer patients and their families.

A maximum of five interventions per each phase of the illness trajectory could be retained. Expert nurses also had to specify the number of minutes deemed adequate to perform each of the selected interventions in a typical case, including the time for documentation tasks. Once the PNOs identified these interventions individually, they shared them with the group. This stage was followed by a period of discussion and clarification. The last step was a secret electronic vote to put the interventions in the order PNOs felt the most important. This procedure followed the classic approach of the nominal group technique (Harvey \& Holmes, 2012).

\section{Delphi method}

Selection of participants. The research team obtained the permission of the DGC assistant director to directly contact PNOs who are practising in Quebec and have a valid email address filed with the DGC. Therefore, the entire population of PNOs in Quebec was selected.

Questionnaires. The online platform SurveyMonkey ${ }^{\mathrm{TM}}$ was used to develop the questionnaire based on the 29 interventions selected during the NGT. Respondents had to answer the questions with a "Yes, I agree/No, I don't agree" based on their expertise in regards to the time required to do a good job completing the intervention and meeting the needs of a typical patient (neither too complex nor a simple case). If they disagreed with a statement, participants had to choose an alternate answer among pre-determined choices. For each phase of the cancer trajectory, participants also had to answer this question: "As a PNO, do you intervene with patients during the XYZ phase?" At the end of the questionnaire, demographic information was collected.

A pre-test with four PNOs was performed to validate understanding of the survey, using the cognitive interview technique (Presser et al. 2004). These interviews led to changes in the survey to ensure it was well understood before sharing it with all respondents. Lastly, a question was considered to have reached consensus when $65 \%$ or more respondents agreed with the statement. If consensus was insufficient after the first survey, another round of consultation was carried out until consensus was reached. A letter of introduction provided an overview of the statements for which consensus was reached. Only participants in the first round were asked to participate in the second round.

Analysis. Descriptive statistics were used to determine the presence or absence of consensus for each Delphi questionnaire statement. The results of the Delphi method are then used in the equations underlying the calculations for required staff by taking the number of new cases per year, the target for Quebec at the time of the study in terms of access to a PNO (70\%) and the time spent on non-clinical tasks (22.4\%) into account, and by using 1,885 hours per year to estimate the needs expressed as full-time equivalent (FTE).

Ethics. The protocol developed to reach consensus using the nominal group technique and the Delphi method was submitted to the Institutional Review Board (IRB) at the Faculty of Medicine at McGill University.

\section{RESULTS}

The results will be presented for each of the two phases of this study.

\section{Nominal group technique}

Participants who were selected as experts had, on average, nearly 30 years of experience, including five as PNOs. A vast majority held a bachelor's degree and worked full-time. These data supported the selection of the group of experts. Attaining a balanced representation of the various sites was also fulfilled.

The expert group identified 29 interventions deemed to be priorities in the various stages of the illness trajectory and the time required to perform each of these interventions. For each step of the illness trajectory, five interventions were retained, except for the "post-treatment follow-up" stage, for which only four interventions were retained. Consensus was reached in the selection of interventions. Consensus was also reached on the nature of the interventions required for each step of the illness trajectory. However, consensus was not reached in this group of experts on the time required to carry out the interventions. This list of interventions and the time required were used to develop the Delphi method questionnaire.

\section{Delphi method}

A total of 252 questionnaires were emailed to PNOs and 122 were retained for analysis, making for a $48 \%$ response rate. The sociodemographic characteristics of the respondents for 
the first round are presented in Table 1. Once the questionnaire was compiled, 16/29 of the PNOs' interventions met the pre-established percentage of agreement to declare consensus. The decision was made to prepare a second round to try and reach consensus for the 13 interventions for which consensus had not been reached in the first round.

At the second round, using the Delphi method, the response rate was $68 \%$, or $83 / 122$ questionnaires. Results submitted in the second round revealed that consensus was reached for the time required to accomplish seven of the 13 interventions. Since the time required to perform the six other tasks still did not reach consensus among participants and the percentages obtained for these interventions were very similar to those obtained in the first round, it was decided to put a stop to the process (Boulkedid, Abdoul, Loustau, Sibony, \& Alberti, 2011).
The percentage of agreement using the NGT and for the two Delphi-method rounds for the first step of the cancer trajectory (i.e. announcement of the diagnosis) are illustrated in Table 2 (the results specific to each step of the trajectory are available upon request). The time required of the PNOs for each step of the trajectory corresponds to the sum of the time required for each intervention deemed necessary for this step. Table 3 presents the sum of the time required for each step of the illness trajectory. The time required to perform six of the 29 interventions did not reach consensus after two rounds of consultation. In this situation, the lower and higher values, between which the greatest proportion of respondents fell, were used. The presence of an interval of time in Table 3 indicates that the time required to carry out these interventions was not consensual at this step.

Table 1: Respondent characteristics - Delphi method

\begin{tabular}{|l|c|c|c|c|c|c|c|}
\hline Site & & \multicolumn{3}{|c|}{ Experience (in years) } & \multicolumn{3}{c|}{ Education } \\
\hline & N & Nurse & Oncology & PNO & Bachelor's & Master's & CON(C) \\
\hline Local & 49 & Min. 15 years & $5-6$ years & $4-5$ years & $88 \%$ & $2 \%$ & $26.5 \%$ \\
\hline Regional & 21 & 10 years & $5-6$ years & 4 years & $95 \%$ & $5 \%$ & $38 \%$ \\
\hline Supra-regional & 52 & $10-15$ years & $8-9$ years & $4-5$ years & $88 \%$ & $12 \%$ & $52 \%$ \\
\hline Total & 122 & & & & $89 \%$ & $6.5 \%$ & $39 \%$ \\
\hline
\end{tabular}

Table 2: Level of agreement on the interventions and the time required during the announcement of the diagnosis phase

\begin{tabular}{|c|c|c|c|}
\hline & \multicolumn{2}{|c|}{ Delphi } \\
\hline & & R1 & R2 \\
\hline Interventions & $\begin{array}{c}\text { Time } \\
(\min .)\end{array}$ & \begin{tabular}{|} 
Level of \\
agreement \\
$(\%)$
\end{tabular} & $\begin{array}{l}\text { Level of } \\
\text { agreement } \\
\text { (\%) }\end{array}$ \\
\hline $\begin{array}{l}\text { 1- Assess the bio-psycho-social and other needs } \\
\text { (initial data collection with patients and their } \\
\text { families) }\end{array}$ & 180 & 61 & 70 \\
\hline $\begin{array}{l}\text { 2- Provide information on the cancer diagnosis, } \\
\text { treatments, exams, steps to come and available } \\
\text { resources }\end{array}$ & 120 & 61 & 70 \\
\hline $\begin{array}{l}\text { 3- Meet patients and their families to support } \\
\text { them during the announcement of the diagnosis } \\
\text { or to intervene should there be a crisis around the } \\
\text { announcement }\end{array}$ & 60 & 83 & \\
\hline $\begin{array}{l}\text { 4- Assess and manage patient symptoms (e.g. pain, } \\
\text { shortness of breath, diarrhea, constipation, } \\
\text { anxiety) prior to treatments (often connected with } \\
\text { the illness) }\end{array}$ & 60 & 63 & 75 \\
\hline $\begin{array}{l}\text { 5- Coordinate the required services, facilitate the } \\
\text { coordination of extensive check-up exams, ensure } \\
\text { communication with patients, communicate problems } \\
\text { and challenges to members of the interdisciplinary } \\
\text { teams and ensure requests for references }\end{array}$ & 75 & 74 & \\
\hline Total & 495 & & \\
\hline
\end{tabular}

\begin{tabular}{|l|l|}
\hline \multicolumn{2}{|l|}{ Table 3: Results of the experts' } \\
consensus expressed in minutes
\end{tabular}


It is necessary to keep in mind that each cancer journey is unique. For example, a patient may not need radiation therapy or will not go into palliative care. Each phase of the cancer trajectory should be taken on its own and only the phases specific to each patient may be added up.

These data show the current situation of this group of PNOs and provide insight into human resources planning. PNOs are found to be mainly involved in the announcement of the diagnosis, chemotherapy, post-treatment follow-up and the transition to palliative care; they are much less involved in surgery and radiation therapy.

\begin{tabular}{|l|l|l|l|l|}
\hline \multicolumn{5}{|l|}{ Table 4: Proportion of PNOs involved, per phase and level } \\
\hline Phase & Local & Regional & $\begin{array}{l}\text { Supra- } \\
\text { regional }\end{array}$ & Total \\
\cline { 2 - 5 } & $\%$ involved & $\%$ involved & $\%$ involved & $\%$ involved \\
\hline $\begin{array}{l}\text { Announcement } \\
\text { of the diagnosis }\end{array}$ & 100 & 100 & 100 & 100 \\
\hline Surgery & 65 & 52 & 62 & 61 \\
\hline Chemotherapy & 93 & 100 & 96 & 96 \\
\hline $\begin{array}{l}\text { Radiation } \\
\text { therapy }\end{array}$ & 49 & 67 & 79 & 67 \\
\hline $\begin{array}{l}\text { Post-treatment } \\
\text { follow-up }\end{array}$ & 97 & 95 & 88 & 93 \\
\hline $\begin{array}{l}\text { Transition to } \\
\text { palliative care }\end{array}$ & 96 & 100 & 100 & 98 \\
\hline
\end{tabular}

The percentage $(22.4 \%)$ is used to quantify the time devoted to related tasks inherent to the work organization (i.e. non-clinical tasks) and must be added to the results obtained by the Delphi method. Finally, epidemiological information about the number of new patients every year must be added according to the phases of the care trajectory. These data come from various sources. The estimate must also take into account the ministerial target that $70 \%$ of new cases access a PNO. Moreover, we used 1,885 hours for the basis of calculation for a full-time PNO (full-time equivalency; FTE). According to these parameters, the equation used to estimate the required staff is as follows:

$$
\begin{gathered}
\text { FTE }=\text { Number of new cases } \times 70 \% \times\left(\text { time required }\left(\frac{\min }{\text { case }}\right)+22.4 \%\right) \div 60 \frac{\min }{\mathrm{Hr}} \\
\quad \div 1,885 \frac{\mathrm{Hr}}{\mathrm{FTE}}
\end{gathered}
$$

For example, for the "Announcement of the diagnosis":

$$
\begin{aligned}
\text { FTE number } & =46,400 \text { cases } \times 70 \% \times\left(495 \min \left(\frac{\mathrm{min}}{\text { case }}\right)+22.4 \%\right) \div 60 \frac{\mathrm{min}}{\mathrm{Hr}} \\
& \div 1,885 \frac{\mathrm{Hr}}{\mathrm{TC}}
\end{aligned}
$$

Number FTE $=$ I73.4

\section{DISCUSSION}

The goal of this study was to reach a professional consensus specifying the interventions that pivot nurses in oncology deem essential for patients throughout the illness trajectory, as well as the time required to perform these interventions.
These data fill gaps in the information required for better human resources planning of PNOs in Quebec and offer a method to inform decision-making about how to distribute this staff. Based on PNOs' professional assessment, this study identified 29 priorities in caring for cancer patients, as well as the time required to accomplish these tasks. The results call into play at least two fundamental issues in the staffing of this professional group. The first is that the intervention time these patients require, according to the PNOs, means that the demand for nursing care greatly exceeds the current service offer based on the number of new cases every year in Quebec. As a consequence, some patients will not have access to this service, as the offer is less than the demand. A second issue is the efficacy of the role, as PNOs perceive it.

The first issue-that the current number of PNOs does not reach the target of $70 \%$ of cancer patients accessing a PNO_calls for certain strategies to be put in place. However, the options are somewhat limited. One is to increase the service offering by recruiting more pivot nurses. Although this option has been implemented, hiring has never corresponded to the needs identified in this study. Another option is to increase the service offering by increasing productivity (Birch et al., 2007). The time devoted to related work-organization tasks (i.e., non-clinical tasks) is comparable to that already reported in the literature (Hendrich, Chow, Skierczynski, \& Lu, 2008). In this context, the capacity to increase the service offering by increasing productivity is possible, but will offer limited gains.

One of the most promising strategies to overcoming this challenge is probably identifying the patients who will most benefit from a PNO's intervention, given her specific role and contribution. These patients can be identified by targeting the most at-risk clienteles and through a better understanding of the impacts of PNOs' interventions.

Certain scales for identifying at-risk patients exist in other fields, particularly geriatrics (Hoogerduijn et al., 2007; Bissett, Cusick, \& Lannin, 2013). This need to properly identify at-risk clienteles is, furthermore, one of the top recommendations of a recent systematic review on the role of care coordinator (Conway, O’Donnell, \& Yates, 2017). More specifically, the authors recommend a system that facilitates the identification of at-risk clienteles, such as older age, comorbidities, and education levels.

To identify these criteria, an exercise of professional consensus with 70 pivot nurses in oncology was carried out at the annual conference of the Association québécoise des infirmières en oncologie (AQIO) in 2013. In terms of the criteria for identifying which patients and families need PNO support, results brought up the following themes: stage of illness, comorbidity, psychosocial condition and multiple treatments. The criteria retained to terminate follow-up (death, transfer to another centre or to palliative care) are based on long-term monitoring, which is inherent to the current conception of the PNO role.

The current information on predictive factors or screening (detection) tools that identify the particular needs of a person suffering from cancer generally fall under three themes: emotional distress, cancer symptoms and their treatments, and 
functional status (Abernathy et al., 2010; Breen et al., 2012; Carlson, 2012). These are very similar to those the PNOs identified in the workshop.

In the MSSS's Direction générale de cancérologie 20162017 Action Plan, under the section on optimizing cancer patients' access to PNOs, the development of three clinical tools is planned. These are: request for consultation, criteria for prioritizing requests and a single-window access with a triage team. The studies quoted above have contributed to the development of these tools. The efficacy of these tools in identifying priority clienteles should be assessed upon their implementation.

This better prioritization and, in parallel, the greater understanding of the patient benefits stemming from PNO support, probably constitutes the two main research avenues to pursue to maximize this role in the coming years. In one study (Paskett, 2011), the efficacy of navigation seems more important during cancer screening than at diagnosis and treatment follow-up; it is also recognized as more important for the adoption of healthy behaviours, particularly during screening and treatment follow-up (Ali-Faisal, Colella, Medina-Jaudes, and Benz, 2016). Another study (Bellomo, 2014) found that patients receiving the support of a PNO report a better continuity of care and level of satisfaction.

It would seem that the Quebec model of PNO deployment has especially emphasized the longitudinal follow-up during the announcement of the diagnosis and during treatment, as shown by the time devoted to follow-up during chemotherapy. Research should be pursued to better document which interventions of the model are the most useful during treatment follow-up.

Although the need to better document the impact on patient health of PNOs' intervention during treatment continues to be felt, this model does indeed seem to positively affect patients' care experience. The latest Quebec survey on patient experience (Dubé-Linteau, 2014) showed that patients who had access to

\section{REFERENCES}

Abernathy, A.P et al. (2010). Utility and use of palliative care screening tools in routine oncology practice. Cancer Journal, 16(5), 444-460.

Ali-Faisal, S.F., Colella, T.J.F., Medina-Jaudes, N., Benz, L. (2016). Do patient navigators improve cancer care utilization behaviors? A meta-analysis. Journal of Oncology and Survivorship, 7(9).

Ali-Faisal, S.F., Colella, T.J.F., Medina-Jaudes, N., Scott, L.B. (2017). The effectiveness of patient navigation to improve healthcare utilization outcomes: A meta-analysis of randomized controlled trials. Patient Education and Counseling, 100(3), 436-448.

Attieh, S., Loiselle, C., Thomas, D., Ehrler, A., Allard, M., Tardif, L., \& Rouseau, C. (2018). The pivot nurse navigator role is linked to significantly higher quality of the patient reported cancer experience. In Preparation.

Bellomo, C. (2014). The effect of navigation intervention on continuity of care and patient satisfaction of patient with cancer. Journal of Oncology Navigation \& Survivorship, 5(6).

Birch, S., Kephart, G., Tomblin-Murphy, G., O’Brien-Pallas, L., Alder, R., \& MacKenzie, A. (2007). Human resources planning and the production of health: A needs-based analytical framework. Canadian Public Policy, 33, S1-S16. a PNO are more likely to rate the quality of care and services they received to be "excellent" or "very good." Moreover, this positive difference is reported for all of the six dimensions of quality: (1) accessibility; (2) coordination and continuity of care; (3) emotional support; (4) information, communication and education; (5) physical comfort; and (6) respect of patient preferences. Attieh and Loiselle (2018) obtained very similar results in their recent study comparing patient care with and without follow-up by a PNO. The findings once again show a significant difference in their care and level of satisfaction.

\section{Limitations}

Whatever the approach, it remains difficult to estimate with any precision the time necessary to give quality nursing care. For example, the organizational factors of each setting were not taken into consideration. Using a computerized patient file will affect the time a nurse requires for documentation. These factors can explain, in part, why the time required to perform certain nursing interventions did not reach consensus in this study. Despite these limits, the approach used (professional consensus) was the best option for estimating $\mathrm{PNO} /$ human resources planning, given the absence of evidence on the relationship between the number of PNOs being deployed and the results on the health of the population being served.

\section{CONCLUSION}

All the steps using the nominal group technique and the Delphi method made it possible to reach professional consensus among a group of experts and to validate this consensus with a larger sample to then go on to generate data on the time PNOs require to perform the 29 interventions deemed necessary for a typical patient in the various stages of the illness and care trajectory. These results support decision-making in staffing at local, regional, and provincial levels, ensuring the active participation of professionals in the decisions that directly affect their efforts to offer patients quality services.

Biron, A.D., \& Saucier, A. (2012). Infirmière pivot en oncologie : Estimation des besoins en effectifs selon la cible ministérielle du Québec. Direction québécoise de cancérologie, Montréal.

Bissett, M., Cusick, A., \& Lannin, N.A. (2013). Functional assessments utilised in emergency departments: a systematic review. Age and Ageing, 42(2), 163-172.

Boulkedid, R., Abdoul, H., Loustau, M., Sibony, O., \& Alberti, C. (2011). Using and reporting the Delphi method for selecting healthcare quality indicators: A systematic review. PloS One, 6(6), e20476.

Breen, S., Ristevski, E., \& Regan, M. (2012). Enabling supportive care screening and evidence-based referrals for patients with cancer: Patient acceptability and clinician implementation of the Supportive Care Resource Kit (SCRK). Australian Journal of Cancer Nursing, 13(1), 20.

Canadian Cancer Society's Advisory Committee on Cancer Statistics (2014). Canadian Cancer Statistics 2014. Toronto, ON: Canadian Cancer Society.

Carlson, L.E., Waller, A., \& Mitchell, A.J. (2012). Screening for distress and unmet needs in patients with cancer: Review and recommendations. Journal of Clinical Oncology, 30(11), 1160-1177. 
Comité consultatif des infirmières en oncologie (2008). Rôle de l'infirmière pivot en oncologie. Québec: Direction de la lutte contre le cancer [DLCC], MSSS.

Comité de l'évolution de la pratique infirmière en oncologie (CEPIO) (2005). Pour optimiser la contribution des infirmières à la lutte contre le cancer. Québec : Programme québécois de lutte contre le cancer, Ministère de la santé et des services sociaux (MSSS).

Conway, A., O'Donnel, C., Yates, P. (in press). The effectiveness of the nurse care coordinator role on patient-reported and health service outcomes : A systematic review. Evaluation a the Health Professions.

Direction de la lutte contre le cancer [DLCC] (2011). Rapport d'activités 2010-2011. Québec : Direction des communications du ministère de la Santé et des Services sociaux du Québec.

Direction de la lutte contre le cancer (2007). Rapport d'activités 20062007. Québec: Direction des communications du ministère de la Santé et des Services sociaux du Québec.

Dubé-Linteau, A. (2014). Enquête québécoise sur la qualité des services de lutte contre le cancer 2013 : L'infirmière pivot en oncologie et l'expérience patient. Québec: Institut de la statistique du Québec.

Evans, C., Rogers, S., \& McGraw, C. (2004). Using consensus methods to establish multidisciplinary perspectives on research priorities for primary care. Primary Health Care Research and Development, 5.

Jones, J., \& Hunter, D. (1995). Qualitative Research: Consensus Methods for Medical and Health Services Research. BMJ, 311(5 August).

Fillion, L., Aubin, M., de Serres, M., Robitaille, D., Veillette, A.M., $\&$ Rainville, F. (2010). The process of integrating oncology nurse navigators into joint hospital-community local teams. Canadian Oncology Nursing Journal, 20(1), 30-35.

Fillion, L., de Serres, M., Cook, S., Goupil, R.L., Bairati, I., \& Doll, R. (2009). Professional patient navigation in head and neck cancer. Semin Oncol Nurs, 25(3), 212-221.
Harvey N., \& Holmes, C.A. (2012). Nominal group technique: An effective method for obtaining group consensus. International Journal of Nursing Practice, 18(2), 188-194.

Hasson, F., \& Keeney, S. (2011). Enhancing rigour in the Delphi technique research. Technological Forecasting and Social Change, 78(9), 1695-1704.

Hendrich, A., Chow, M.P., Skierczynski, B.A., \& Lu, Z. (2008). A 36-hospital time and motion study: how do medical-surgical nurses spend their time? The Permanente Journal, 12(3), 25.

Hoogerduijn, J.G., Schuurmans, M.J., Duijnstee, M.S., De Rooij, S.E., Grypdonck, M.F. (2007). A systematic review of predictors and screening instruments to identify older hospitalized patients at risk for functional decline. Journal of Clinical Nursing, 16(1), 46-57.

Kohli, E., Ptak, J., Smith, R., Taylor, E., Talbot, E.A., \& Kirland, K.B. (2009). Variability in the Hawthorne Effect with regard to hand hygiene performance in high and low performing inpatient care units. Infection Control and Hospital Epidemiology, 30(3), 222-225. doi:10.1086/595692

Paskett, E.D., Harrop, J., \& Wells, K.J. (2011). Patient navigation: An update on the state of the science. CA: A Cancer Journal for Clinicians, 61(4), 237-249.

Plante, A., \& Joannette, S. (2009). Monteregie Comprehensive Cancer Care Centre: Integrating nurse navigators in Monteregie's oncology teams: Oone aspect of implementing the Cancer Control Program-Part 1]. Can Oncol Nurs J, 19(1), 13-18.

Presser, S., Couper, M.P., Lessler, J.T., Martin, E., Martin, J., Rothgeb, J.M., \& Singer, E. (2004). Methods for testing and evaluating survey questions. Public Opinion Quarterly, 68(1), 109-130.

Spetz, J., Donaldson, N., Aydin, C., \& Brown, D.S. (2008). How many nurses per patient? Measurements of nurse staffing in health services research. Health Services Research, 43(5p1), 1674-1692. 